\title{
Morphological, chemical and optical absorbing characterization of aerosols in the urban atmosphere of Valladolid
}

\author{
S. Mogo ${ }^{1,2}$, V. E. Cachorro ${ }^{1}$, and A. M. de Frutos ${ }^{1}$ \\ ${ }^{1}$ Grupo de Óptica Atmosférica, Universidad de Valladolid, Valladolid, Spain \\ ${ }^{2}$ Dep. de Física, Universidade da Beira Interior, Covilhã, Portugal
}

Received: 28 February 2005 - Published in Atmos. Chem. Phys. Discuss.: 13 June 2005

Revised: 9 August 2005 - Accepted: 29 September 2005 - Published: 19 October 2005

\begin{abstract}
Samples of atmospheric aerosol particles were collected in Valladolid, Spain, during the winter of 20032004. The measurements were made with a Dekati $\mathrm{PM}_{10}$ cascade impactor with four size stages: greater than $10 \mu \mathrm{m}$, between 2.5 to $10 \mu \mathrm{m}, 1$ to $2.5 \mu \mathrm{m}$ and less than $1 \mu \mathrm{m}$. The size and shape of the particles were analyzed with a scanning electron microscope (SEM) and elemental analysis was done with an energy dispersive $\mathrm{x}$-ray analysis (EDX). We present an evaluation by size, shape and composition of the major particulate species in the Valladolid urban atmosphere.

The total aerosol concentration is very variable, ranging from $39.86 \mu \mathrm{g} \cdot \mathrm{m}^{-3}$ to $184.88 \mu \mathrm{g} \cdot \mathrm{m}^{-3}$ with the coarse particles as the dominant mass fraction. Emphasis was given to fine particles $(<1 \mu \mathrm{m})$, for which the visible $(400 \mathrm{~nm}$ to $650 \mathrm{~nm}$ ) light absorption coefficients were measured using the integrating plate technique. We have made some enhancements in the illumination system of this measurement system. The absorption coefficient, $\sigma_{a}$, is highly variable and ranges from $7.33 \times 10^{-6} \mathrm{~m}^{-1}$ to $1.01 \times 10^{-4} \mathrm{~m}^{-1}$ at a wavelength of $550 \mathrm{~nm}$. There is an inverse power law relationship between $\sigma_{a}$ and wavelength, with an average exponent of -0.8 .
\end{abstract}

\section{Introduction}

The importance of aerosols has been stressed many times in the past few decades. For example a great number of studies have looked at their influence on climate change through their contribution to radiative forcing (Haywood and Boucher, 2000; Roberts and Jones, 2004; Hansen and Nazarenko, 2004). In this context the study of aerosols is focused on those of anthropogenic and natural origin.

Correspondence to: S. Mogo

(smogo@dfisica.ubi.pt)
It is well known that aerosols directly affect climate through changes in the optical depth, i.e., the vertical integral of the particle extinction coefficient. Hence, the knowledge of the scattering and absorptive properties of aerosols is of utmost importance. Regardless of the huge number of studies of the radiative properties of aerosols, their net effect on global climate change is uncertain since the effect of particles can be to cool or to warm, depending on their size and at what altitude they are found (Hänel and Hillenbrand, 1989; Wang, 2004). The particle properties show in general a great spatial and temporal variability.

The scattering and absorption of light by particles depends also on their elemental composition. At present sulphate aerosols are considered the primary particles responsible for net cooling. They scatter solar radiation and are effective as cloud condensation nuclei, resulting in a negative radiative forcing that leads to a cooling of the Earth surface. On the other hand, soot, or black carbon (BC) is an effective absorber of solar radiation and has, therefore, a warming effect.

The particles' optical properties also depend on how various aerosol species are mixed, i.e., if they form an internal mixture, an external mixture or a core-shell structure (Chandra et al., 2004). For example, the absorption coefficient of a mixture of elemental carbon with non-absorbent particles is larger for an internal mixture than for an external mixture (Horvath, 1993). This underscores that studies of aerosol composition should not be taken apart from the study of their optical and radiative characteristics.

As part of a general characterization study of the urban aerosol in the city of Valladolid, this work categorizes the morphology and elemental composition and analyzes their light absorbing characteristics as related to the elemental components and range of sizes. The classification took into account the results of scanning electron microscopy and energy dispersive $\mathrm{x}$-ray analysis. The scanning electron microscope provides high resolution images of the particles and the energy dispersive $\mathrm{x}$-ray analysis provides information about

(C) 2005 Author(s). This work is licensed under a Creative Commons License. 


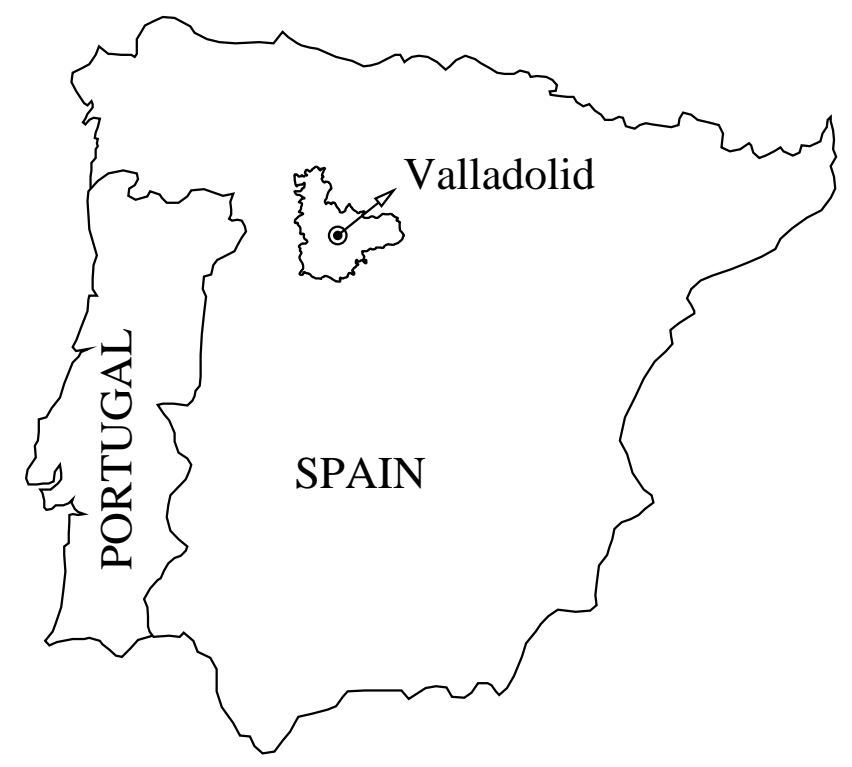

Fig. 1. Map of Spain. Valladolid is situated in the north-center of the Iberian Peninsula.

the composition. In this way the classification is simultaneously based on the chemical and morphological characteristics of the aerosol leading to a better qualitative description of the atmospheric particles. This analysis approach follows previously published studies of aerosol particles properties using a similar technique (e.g., Ramsden and Shibaoka, 1982; Anderson et al., 1992; McMurry et al., 1996; Buseck and Pósfai, 1999; Pósfai et al., 2003).

\section{Experimental}

\subsection{Sampling location and method}

The particles used in this study were collected within the urban environment of Valladolid, Spain $\left(41.67^{\circ} \mathrm{N}, 4.74^{\circ} \mathrm{E}\right)$, during the extended winter, December 2003 to March 2004. Valladolid is a medium size town with $\approx 500000$ inhabitants located in the north-center of the Iberian Peninsula (see Fig. 1). It is the largest town of the extended region of "Castilla y León" which occupies the main part of north central Spain. The type of surface that surrounds the city is basically rough, bare and dry soil used primarily for agriculture. The urban aerosol corresponds to a lightly industrialized city whose contamination mostly comes from road traffic and domestic heating; however, no emission source inventory has been developed for this city. The pollution levels are strongly dependent on the atmospheric synoptic conditions, in this case a long and cold winter, with frequent fog events. These fog events are due to the Pisuerga River Valley within which lies the city. The relative humidity ranges from $83 \%$ in January to $47 \%$ in July, with an annual mean of
Table 1. Characteristics of the cascade impactor DEKATI PM10. Air flow: $16.5 \mathrm{l} / \mathrm{min}$. Sizes are aerodynamic equivalent diameter.

\begin{tabular}{ccc}
\hline Stage & Size range $/ \mu \mathrm{m}$ & Modal regime \\
\hline 0 & $<1$ & fine \\
1 & $1-2.5$ & coarse \\
2 & $2.5-10$ & coarse \\
3 & $>10$ & coarse \\
\hline
\end{tabular}

approximately $65 \%$. Mean monthly precipitation varies from $56 \mathrm{~mm}$ in December to $16 \mathrm{~mm}$ in July and an annual mean total of $435 \mathrm{~mm}$. The predominant wind direction follows the line of the river valley (NE-SW). Typical directions are from NE (25\%), SW (23\%), N (20\%), S (10\%) and others (20\%). However, we must mention that there is $\approx 25 \%$ of calm wind days.

The sampling site was on the campus of the Valladolid University and the impactor was located on a small terrace on the second floor of the four story building of the Sciences Faculty, $\approx 150 \mathrm{~m}$ from the nearest main road. The building partially shields the impactor from southerly winds but this is not relevant for the present study because the levels of mass concentrations are generally linked with well defined synoptic situations with quantifiable apportioning for two extreme situations: very clean, when winds are mostly northerly and air masses come from the Arctic and highly polluted, corresponding to the anticyclonic weather (Sánchez et al., 1990). Very peculiar and extreme situations are given by desert dust intrusions over Spain (estimated about 6-8\% of days per year) that originate the episodes of higher particulate matter concentration for very well defined synoptic weather conditions (Rodríguez et al., 2001; Querol et al., 2004).

A Dekati $\mathrm{PM}_{10}$ impactor was used to collect the particles on Millipore polycarbonate membrane filters with $0.2 \mu \mathrm{m}$ pores. The impactor had a constant flow rate of $16.51 / \mathrm{min}$ and the sampling times varied from 8 to $15 \mathrm{~h}$. The sampling took place during the night (usually starting at 08:00 p.m., local time) and fog events were avoided. The impactor aerodynamic cut-off diameters are presented in Table 1.

Sampling times were limited by the amount of aerosol needed for the analysis with the integrating plate technique that is used to evaluate the absorption coefficient for particles smaller than $1 \mu \mathrm{m}$, as discussed in Sect. 2.3.

\subsection{Experimental methods: microanalysis of samples}

Particle analysis was performed using a HITACHI SEM2700 , scanning electron microscope, that provides high resolution images of the particles. This allowed a classification of the particles based on the morphology. The microscope was equipped with a RONTEC energy dispersive x-ray system in order to obtain information about elemental composition of the particles. A peak search program was used to identifiy 
the elements in the x-ray spectrum of each particle that was analyzed. This method allows the identification and posterior classification of different particles that share the same morphology, by using their elemental signatures.

2.3 Experimental methods: absorption coefficients determination

Most of the difficulties in assessing the radiative net effect of the aerosols are due to uncertainties in the evaluation of the absorption coefficient that is usually much smaller than the scattering coefficient. Although, the extinction coefficient can be determined with a given precision using a white cell, exact splitting of the two contributions, absorption and scattering, is not an easy task and has a very high uncertainty, especially the determination of the absorption coefficient.

In the current study the absorption coefficients were evaluated by measuring the transmission of light through every filter before and after the aerosol collection. The method used is an adaptation of the well known integrating plate method (Lin et al., 1973), with some changes from the original method in the illumination and detection systems.

The light source was provided by a $50-\mathrm{W}$ tungsten halogen lamp. A monochromator was laid between the light and the integrating plate. This allows the filter to be illuminated with monochromatic light with a wavelength dependent on the diffraction grating of the monochromator. The detection system was a simple photosensor. With this approach several wavelengths in the visible spectral region can be used. The monochromator spectral window is $400-650 \mathrm{~nm}$ with a $50 \mathrm{~nm}$ resolution. The diagram of the measurement system is shown in Fig. 2.

Absorption coefficients $\left(\sigma_{a}\right)$ of particle samples with aerodynamic size below $1 \mu \mathrm{m}$ were determined by measuring the apparent transmission, $T(\lambda)$, of the incident light through the polycarbonate filter:

$T(\lambda)=\frac{I_{f}(\lambda)}{I_{0}(\lambda)}$,

where $I_{f}(\lambda)$ and $I_{0}(\lambda)$ are the intensities of light passing through the loaded and unloaded filter, respectively, for each wavelength. Assuming that the attenuation of the light beam follows the Beer-Lambert law, one has:

$I_{f}(\lambda)=I_{0}(\lambda) e^{-x \sigma_{a}(\lambda)}$,

where $x$ is the optical path length calculated from the volume of sampled air and the effective cross-section area of the filter $\left(x=\frac{V}{A}\right)$. The absorption coefficient can be determined knowing $I_{0}(\lambda), I_{f}(\lambda), V$ and $A$ :

$\sigma_{a}(\lambda)=-\frac{A}{V} \ln \frac{I_{f}(\lambda)}{I_{0}(\lambda)}$.

The mass absorption specific coefficient of fine particles, $B_{a}(\lambda)$ is:

$B_{a}(\lambda)=\frac{\sigma_{a}(\lambda)}{M_{\phi<1 \mu \mathrm{m}}}$,
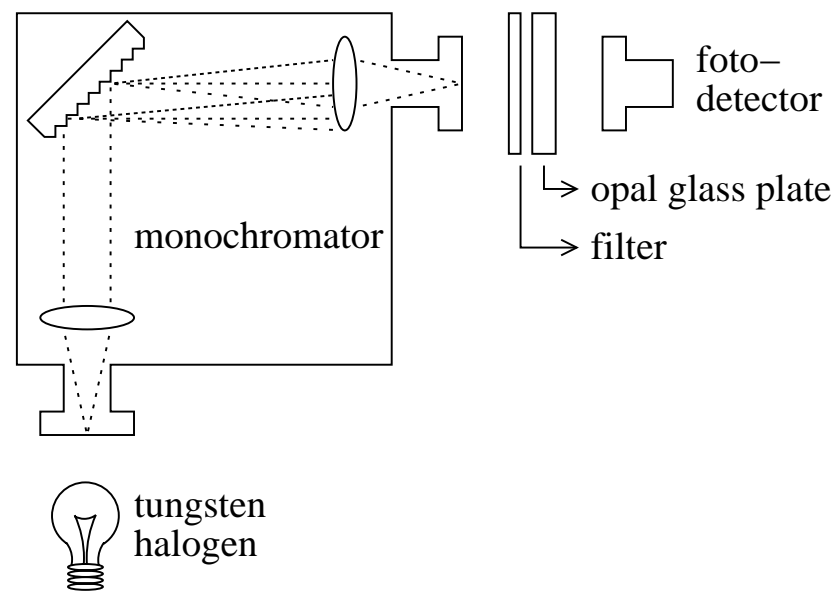

Fig. 2. Schema of the optical system using the integrating plate (opal glass plate) for the analysis of light absorbing aerosols. The light source is a 50-W tungsten halogen lamp. The monochromator can work from $400 \mathrm{~nm}$ to $650 \mathrm{~nm}$. The detection is provided by a photosensor.

where $M_{\phi<1 \mu \mathrm{m}}$ is the mass concentration of fine particles (aerodynamic size below $1 \mu \mathrm{m}$ ).

By using this method, it is assumed that the optical properties of the particles are unchanged by the collection method and that their behavior remain unaltered after collection on the filter.

With a system analogous to ours, it was determined that 9\% of the scattering is measured as absorption (Bond et al., 1999). As we do not measure either scattering or extinction we are unable to correct the absorption values for this error. The method is very reproducible (within 1-2\% margin) but the calibration of the instrument has an uncertainty of $\approx 20 \%$.

The filters were weighed before and after collection for determination of the amount of particulate matter in each impactor stage. The transmission measurements of the clean filter and the loaded filter were separated by $36-46 \mathrm{~h}$ to allow stabilization and acclimatization in the weighing room. Special care was taken in order to remove electrical charges from the filters. Transmission measurements were made through blank filters for testing filters variability. For a 46-h period between the measurements of the blank and the loaded filter no differences were observed.

Based on an evaluation using propagation of errors we estimated an error for $\sigma_{a}$ between $27 \%$ and $39 \%$. The error has a spectral dependence, with larger errors at $400 \mathrm{~nm}$ than at $650 \mathrm{~nm}$. This is related with the low intensity of the light source for the smaller wavelengths and the transmittance of the polycarbonate filter, which are the main sources of error and together represent $80 \%$ of the total error. Other sources of uncertainty are the area of aerosol deposit and the volume of sampled air. The estimated detection limit, for a 24-h average sample, is $1.46 \times 10^{-8} \mathrm{~m}^{-1}$. 
Table 2. Particles sampled on each impactor stage. Values represent the percent of particles in each size stage.

\begin{tabular}{|c|c|c|c|c|c|c|c|c|c|c|c|c|c|c|c|c|}
\hline \multirow{2}{*}{$\begin{array}{l}\text { Elemental } \\
\text { analysis }\end{array}$} & \multicolumn{4}{|c|}{$<1 \mu \mathrm{m}$} & \multicolumn{4}{|c|}{$1-2.5 \mu \mathrm{m}$} & \multicolumn{4}{|c|}{$2.5-10 \mu \mathrm{m}$} & \multicolumn{4}{|c|}{$>10 \mu \mathrm{m}$} \\
\hline & $\mathrm{c}$ & $\mathrm{i}$ & $\mathrm{s}$ & $\mathrm{p}$ & $\mathrm{c}$ & $\mathrm{i}$ & $\mathrm{S}$ & $\mathrm{p}$ & $\mathrm{c}$ & $\mathrm{i}$ & $\mathrm{s}$ & $\mathrm{p}$ & $\mathrm{c}$ & $\mathrm{i}$ & $\mathrm{s}$ & $\mathrm{p}$ \\
\hline S & - & 4 & 15 & - & - & 3 & - & - & - & 6 & - & - & - & 12 & - & - \\
\hline $\mathrm{Cl}$ salts & - & - & - & - & - & 27 & - & - & - & 33 & 12 & - & - & 15 & - & 4 \\
\hline$>\mathrm{Si}, \mathrm{Ca}(\mathrm{Al}, \mathrm{Fe})$ & - & 4 & 4 & - & - & 22 & 5 & - & - & 18 & 3 & 6 & - & 31 & - & 12 \\
\hline$>\mathrm{Si}, \mathrm{Ti}(\mathrm{Ca})$ & - & - & - & - & - & - & - & - & - & - & - & 3 & - & - & - & - \\
\hline $\mathrm{C}$ & 42 & - & 31 & - & 30 & - & 11 & - & 9 & - & - & - & 12 & 4 & - & - \\
\hline$>\mathrm{Fe}$ & - & - & - & - & - & - & 3 & - & - & 6 & - & 3 & - & - & - & - \\
\hline$>\mathrm{Zn}$ & - & - & - & - & - & - & - & - & - & - & - & - & - & 4 & - & - \\
\hline$>\mathrm{Al}$ & - & - & - & - & - & - & - & - & - & - & - & - & - & 4 & - & 4 \\
\hline
\end{tabular}
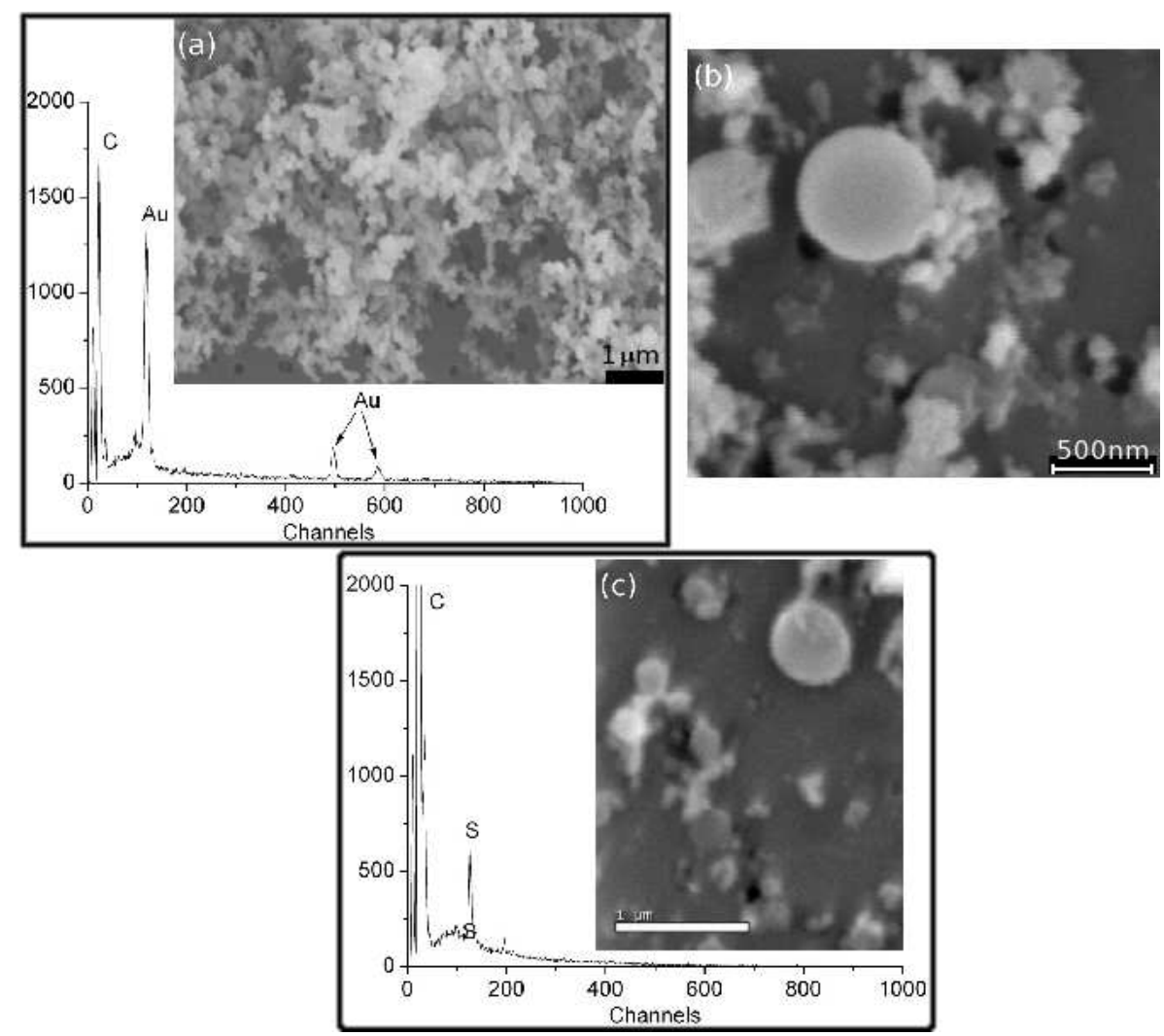

Fig. 3. SEM photo and x-ray spectrum of particles in the range bellow $1 \mu \mathrm{m}$. The darker points are the filter pores. (a) Carbon chains. Gold peaks in $\mathrm{x}$-ray spectrum are due to the gold coating of the filter. (b) Spherical carbon particle. (c) Spherical sulfur-rich particle. The carbon peak is due to the carbon coating of the filter.

\section{Results and discussion}

\subsection{SEM and EDX}

The filters were covered with a conductive layer in order to make them visible in the electron microscope. This coating was made in some cases with a gold layer and in others with a carbon layer. Thus, in the x-ray spectra appears peaks due to either the gold or carbon coating and are ignored when performing the analysis. In the case of carbonaceous parti- cles they can be distinguished from the polycarbonate filter material on which they are collected because they present a much stronger signal than that of the filter. This information together with its morphology was used in order to separate the signal of the particle from that of the polycarbonate filter.

We performed a detailed analysis of 12 filters from three representative days of measurements, From each filter, 20 particles were analyzed for a total of 240. Several classes of particles were detected in each impactor stage from both 

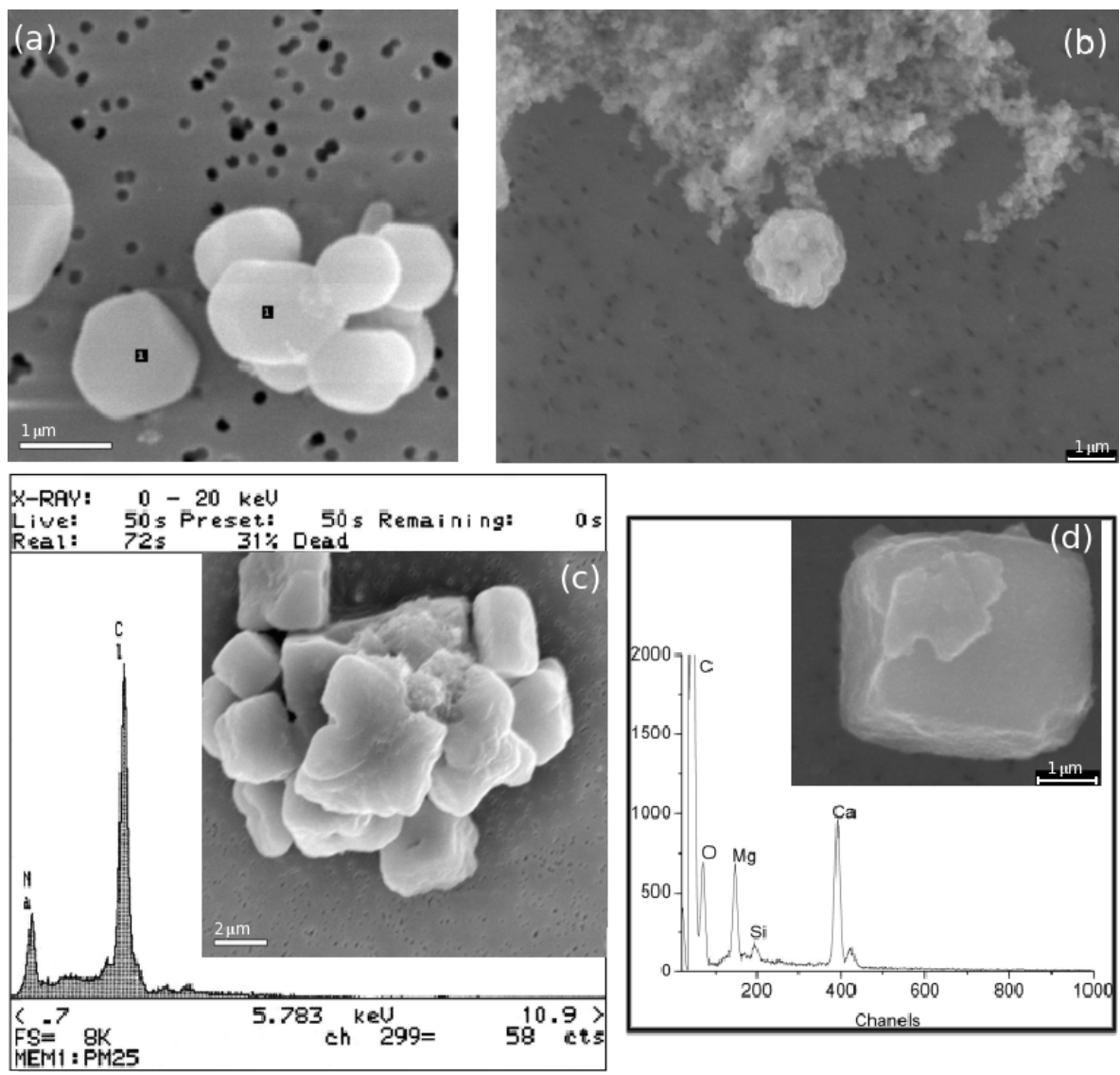

Fig. 4. Particles in the range $1-10 \mu \mathrm{m}$. (a) $\mathrm{NaCl}$ particles. The number refers to analyzed particles. (b) Carbon agglomerate associated with a spherical particle of carbonaceous origin found on stage $1(1-2.5 \mu \mathrm{m})$ of the impactor. (c) $\mathrm{NaCl}$ particles and the respective $\mathrm{x}-$ ray spectrum. (d) Cubic particle and its x-ray spectrum collected on impactor level 2.

natural and anthropogenic sources. Anthropogenic particles, including graphitic carbon (the main constituent of soot) were frequently observed.

For aerosol classification we separated the particles into four basic shapes: chain agglomerates (c), spheres (s), prolonged (p) and irregulars (i) and the composition was divided into eight categories (Table 2):

1. S-rich or sulphate particles: $\left(\mathrm{NH}_{4}\right)_{2} \mathrm{SO}_{4}, \mathrm{CaSO}_{4}, \ldots$;

2. carbonaceous;

3. chlorine salts: $\mathrm{Mg}, \mathrm{K}, \mathrm{Ca}$;

4. crustal : mixtures of $\mathrm{Si}, \mathrm{Ca}, \mathrm{Al}, \mathrm{Fe}, \ldots$;

5. majority silicon and titanium;

6. majority iron;

7. majority aluminum;

8. majority zinc.

The classification of chain agglomerates (c) refers to the typical appearance of submicrometer carbonaceous spheres forming chain-like clusters, the spherical (s) shape refers to round or spherule-like particles, prolonged (p) refers to particles having an oblong or somewhat elongated form and particles with other shapes were classified as irregulars (i). A summary of the analysis for all particles examined in this work is given in Table 2. The elements shown in parentheses, as in $\mathrm{Si}, \mathrm{Ca},(\mathrm{Al}, \mathrm{Fe})$, present only a small signal in the EDX spectrum.

It is important at this point to relate the aerodynamic size in which the impactor separates the particles with the geometric size of the particles observed in the microscope. The SEM shows the particles in a two dimensional view parallel to the plane of the filter and the geometric diameter can be achieved by fitting ellipses to the particle outlines and taking an average of the short and long axes of the best fitting ellipse. The geometric diameter, $\phi_{g}$, and the aerodynamic diameter, $\phi_{a}$, are related by the expression $\phi_{a}=\phi_{g} \kappa \sqrt{\frac{\rho}{\rho_{0}}}$, where $\kappa$ is a factor that accounts for the shape of the particle and its orientation on the filter ( $\kappa=1$ in the case of a sphere), $\rho$ is the density of the particle and $\rho_{0}$ is the reference density $\left(1 \mathrm{~g} / \mathrm{cm}^{3}\right)$. Because of the effect of particle density on the aerodynamic diameter, a spherical particle of high density will have a larger aerodynamic diameter than its geometric diameter. In this work, if nothing is said to the contrary, we will be referring to the aerodynamic size of the particles. 


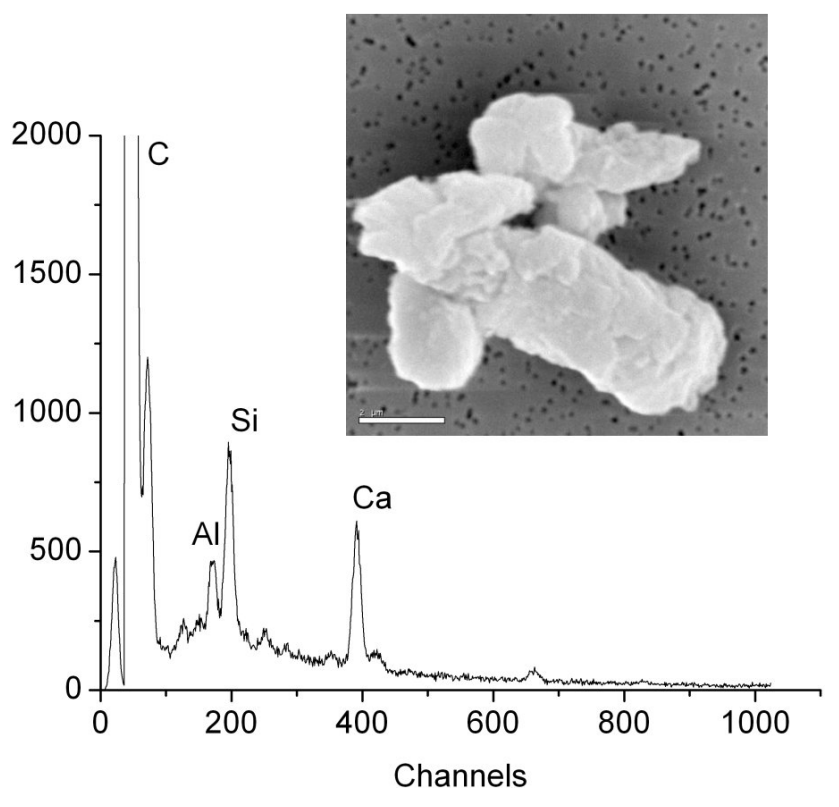

Fig. 5. SEM image and $x$-ray spectrum of a particle rich in silicon, calcium and aluminum. The white bar in the lower left corner corresponds to $2 \mu \mathrm{m}$.

In the particle range below $1 \mu \mathrm{m}$ the most predominant species found were the soot particles, formed by carbon chains (Fig. 3a). Spherical carbon particles were also observed (Fig. 3b). These aerosols are most probably coal and oil fly ash particles. There were also observed spherical sulfur particles (Fig. 3c).

Chloride salt particles, with sizes between 1 and $2.5 \mu \mathrm{m}$, were encountered in the first impactor stage (Fig. 4a) as were other particles mainly composed of silicon, calcium and other minor species. Generally, however, the dominant species in this impactor level were carbonaceous particles (Fig. 4b).

The impactor second stage collected particles with sizes between 2.5 and $10 \mu \mathrm{m}$. The most common particles on this level were the chloride salts, mainly $\mathrm{NaCl}$ (Figs. 4c, d), but also $\mathrm{KCl}, \mathrm{MgCl}_{2}$ or $\mathrm{CaCl}_{2}$. This suggests the existence of some local source that has still not been identified, but previously acknowledged by other authors (Vázquez et al., 2003; Casado et al., 1996) in studies of rainwater monitoring the same region.

The particles larger than $10 \mu \mathrm{m}$ were collected on the third impactor stage. In this range the dominant particles are those rich in silicon, calcium, aluminum and iron. Particles with this composition are present in all the impactor stages and they are most likely from clay as this is the dominant constituent of the local soil. They present in general an irregular form and an x-ray spectrum as that seen in Fig. 5. The Alrich particles found in this level may also be soil-derived.

Figure 6 shows several particles mixed with soot. In Figs. $6 \mathrm{a}, \mathrm{b}$ we can observe a carbon chain attached to a larger
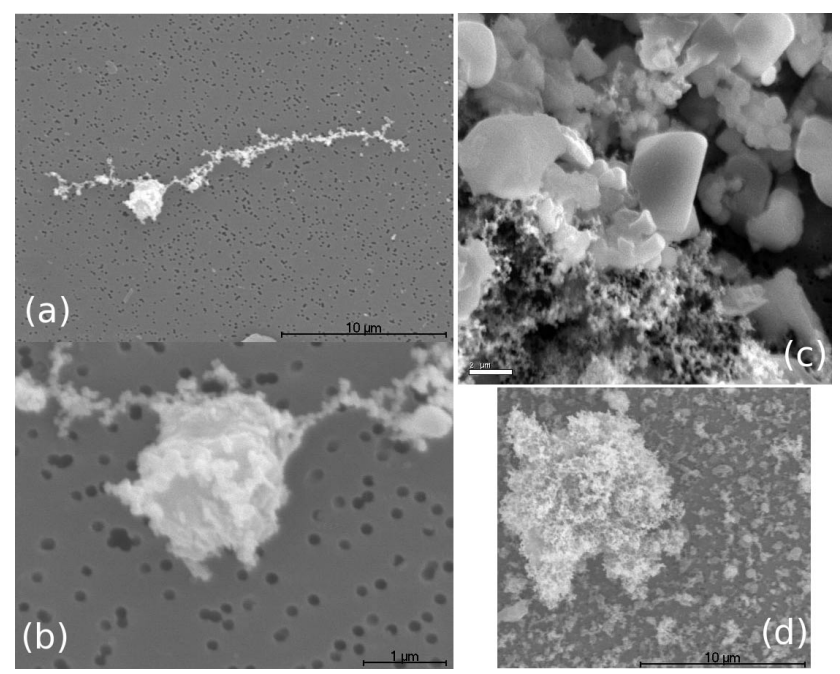

Fig. 6. (a) Chain-like soot monomers attached to a bigger particle. (b) Beneath, with more magnification, it can be seen how the small carbon particles are added to the larger particle. (c, d) Mixture of carbon aggregates with other particles. In (c), the white bar in the lower left corner corresponds to $2 \mu \mathrm{m}$, in (d), the black bar in the lower right corner corresponds to $10 \mu \mathrm{m}$.

spherical particle while in Figs. 6c, d we observe how particles of several origins are contained within a carbon aggregate.

Figure 7 summarizes the information given in Table 2 as frequency distributions stratified by size, elemental composition and shape. Carbonaceous particles are dominant in the range of particle matter $(\mathrm{PM})<2.5 \mu \mathrm{m}\left(\mathrm{PM}_{2.5}\right)$ and they appear predominantly as chains; however, in the range of $\mathrm{PM}<1 \mu \mathrm{m}\left(\mathrm{PM}_{1.0}\right)$ there is a considerable proportion of carbonaceous spherical particles too. In the range of $\mathrm{PM}>2.5 \mu \mathrm{m}$ the dominant particles are chloride salts and those formed by silicon, calcium, aluminum and iron (clays). In the fraction of $\mathrm{PM}_{2.5}, \approx 36 \%$ of the particles observed are carbon aggregates and $\approx 35 \%$ are sphere-like. We found mainly $\mathrm{C}$ and $\mathrm{S}$-rich spheres but spherical iron-rich particles are present too. This could be valuable information in order to determine the aerosol sources since spherical particles are generally indicative of combustion or other high temperature processes characteristic of industrial activities. In the coarse fraction $(\mathrm{PM}>2.5 \mu \mathrm{m})$ the most common shape found is the irregular $(\approx 67 \%)$. Irregular/crustal particles composed of $\mathrm{K}$, $\mathrm{Mg}$ or $\mathrm{Ca}$ are components of sea salt and may be aerosols of maritime origin. S-rich particles with irregular shape can originate from maritime as well as geological sources. Alrich and $\mathrm{Si}, \mathrm{Ca},(\mathrm{Al}, \mathrm{Fe})$ particles are probably soil derived.

We must assume that in the vacuum of the microscope volatile compounds are lost and under the electron beam some particles may change their shape even when a very lowintensity beam is used. Because of this, Fig. 7 refers only to non-volatile components of particulate matter. Another 


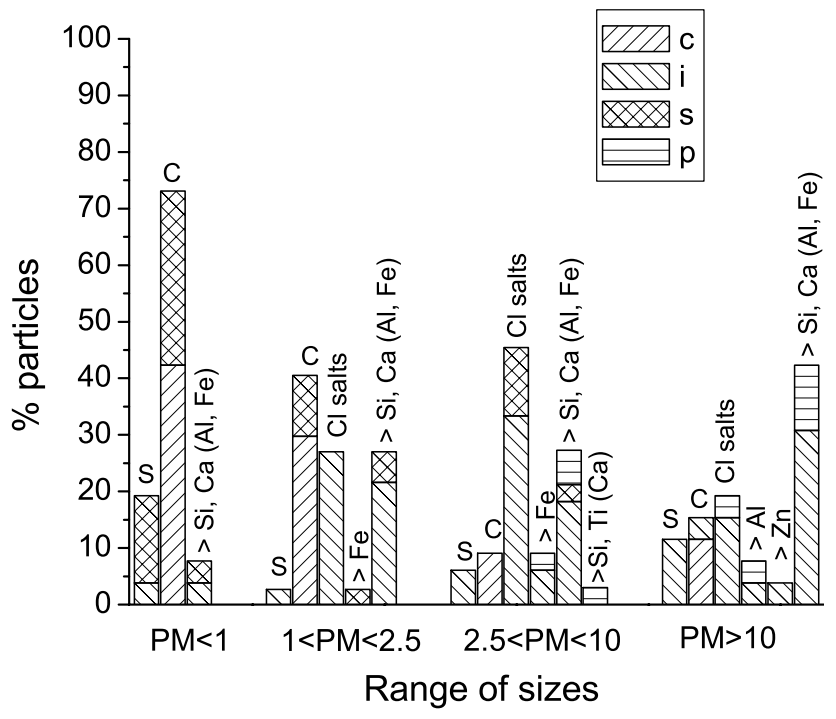

Fig. 7. Frequency distribution of the analyzed particles by size, composition and shape. As in the Table 2, c, i, s and p mean chain agglomerate, irregular, spherical and prolonged, respectively. Each column represents a characteristic elemental composition. 60 particles were analyzed in each range of sizes.

limitation of the SEM is that the method is very laborious and time consuming; nevertheless, it is a powerful tool for detailed characterization of individual aerosol particles.

\subsection{Mass concentration and mass absorption coefficients}

There is a complete lack of information about absorption and scattering coefficients in the atmosphere of Valladolid (neither any other towns from center Spain) and its environment is not comparable to other towns in central Europe because the combination of the aridity and the agricultural usage of the land result in aerosol masses that are high compared to other European cities of similar size and population. This is also true for all of central Spain. The absorption coefficients were measured only for particles with aerodynamic diameters $<1 \mu \mathrm{m}$. Larger particles may potentially contribute to the the overall atmospheric absorption coefficient; however, as discussed in the previous section, the majority of carbonaceous material was found at sizes smaller than $1 \mu \mathrm{m}$. Since elemental carbon is the most predominant light absorber in the atmosphere, the measurements of absorption coefficient that we present here are probably good estimates of the total absorption coefficient.

Figure 8 shows the time variation of the absorption coefficient at visible wavelengths during the periods of sampling. For a wavelength that is close to the middle of the visible spectrum, $550 \mathrm{~nm}$, minimum and maximum values of $7 \times 10^{-6} \mathrm{~m}^{-1}$ and $100 \times 10^{-6} \mathrm{~m}^{-1}$ were measured. The average value for all the campaign period was $45 \times 10^{-6} \mathrm{~m}^{-1}$. After averaging over all wavelengths we get a minimum of

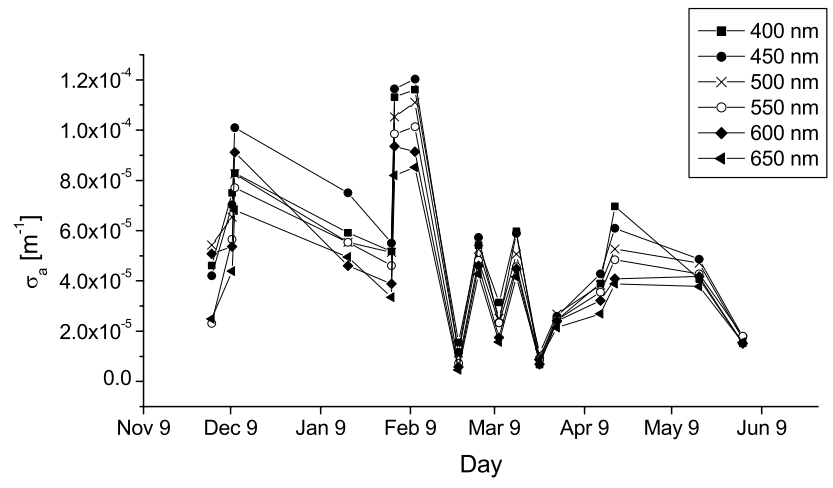

Fig. 8. Time variation of aerosol absorption coefficient during the campaign for $\mathrm{PM}_{1.0}$.

$7 \times 10^{-6} \mathrm{~m}^{-1}$ and a maximum of $100 \times 10^{-6} \mathrm{~m}^{-1}$. The average absorption coefficient observed was $47 \times 10^{-6} \mathrm{~m}^{-1}$. The values of $\sigma_{a}$ measured in Valladolid are comparable in range with the monthly means reported for Melpitz, Germany, $5 \times 10^{-6} \mathrm{~m}^{-1}$ to $80 \times 10^{-6} \mathrm{~m}^{-1}$ (Heintzenberg and Bussemer, 2000 ). Values of $50 \times 10^{-6} \mathrm{~m}^{-1}$ to $250 \times 10^{-6} \mathrm{~m}^{-1}$ were reported for Asian dust with black carbon contamination (Chou et al., 2003).

Figure 9 shows variations of the absorption coefficient through the visible spectrum. The three curves belong to three representative sample days, one particularly high (11 February), one particularly low (26 February) and one normal day (20 April). It can be observed that the absorption coefficient value decreases with the wavelength; however, this decrease is not very pronounced during our measurement period, reaching a maximum difference of $31 \times 10^{-6} \mathrm{~m}^{-1}$ between $400 \mathrm{~nm}$ and $650 \mathrm{~nm}$, a minimum difference of $3 \times 10^{-6} \mathrm{~m}^{-1}$ and an average of $18 \times 10^{-6} \mathrm{~m}^{-1}$. The wavelength dependence of the absorption coefficient can be approximated by $\sigma_{a}=K \lambda^{-\alpha_{a}}$, where $K$ is a constant, $\lambda$ is the wavelength of light and $\alpha_{a}$ is the alpha exponent for absorption. For an aerosol whose absorption coefficient has no wavelength dependence, $\alpha_{a}=0$. An urban aerosol value of $\alpha_{a}=1$ has been reported (Rosen et al., 1979; Kirchstetter et al., 2004). The average $\alpha_{a}$ value for all the days of our campaign is 0.8 . On the day with relatively high absorption coefficients it can be seen that the trend with wavelength is somewhat different than the other days, i.e., there is almost no difference between $400 \mathrm{~nm}$ and $500 \mathrm{~nm}$. On the other hand, because of the estimated uncertainty in the measurement, shown by the vertical bars, these differences are within the expected accuracy of the measurement.

Figure 10 shows a time series of total particulate matter (TPM), $\mathrm{PM}_{1.0}$, and the ratio of coarse to fine mode $(\mathrm{C} / \mathrm{F})$ during the campaign period. TPM values vary from $40 \mu \mathrm{g} \cdot \mathrm{m}^{-3}$ to $185 \mu \mathrm{g} \cdot \mathrm{m}^{-3}$ and the average for all the campaign days was $108 \mu \mathrm{g} \cdot \mathrm{m}^{-3}$. Fine particle concentrations ranged between $10 \mu \mathrm{g} \cdot \mathrm{m}^{-3}$ and $54 \mu \mathrm{g} \cdot \mathrm{m}^{-3}$ with an average 


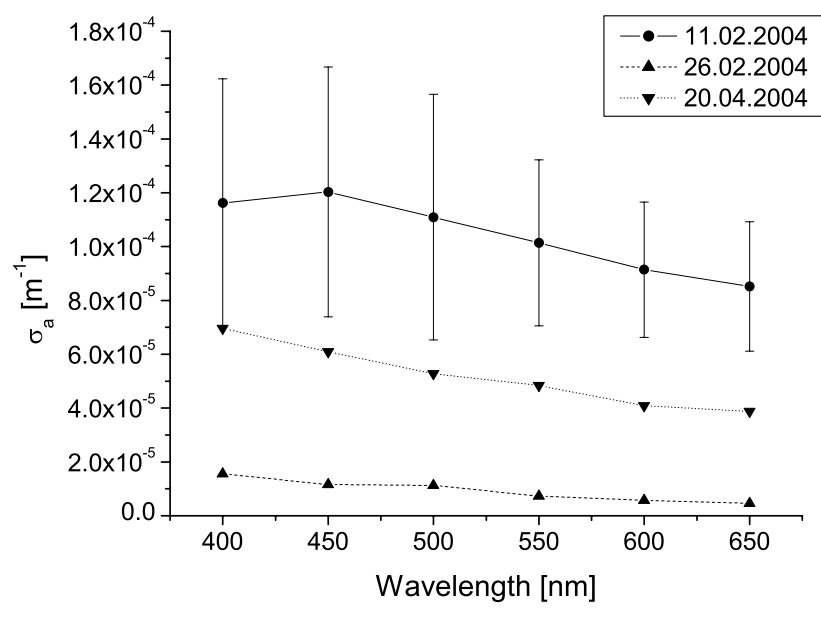

Fig. 9. Aerosol absorption coefficient variation within the visible spectrum. The different lines belong to three example days: one particularly high, 11 February $(\bullet)$; one particularly low, 26 February $(\boldsymbol{\Lambda})$; and one normal day, 20 April ( $\mathbf{\nabla})$.

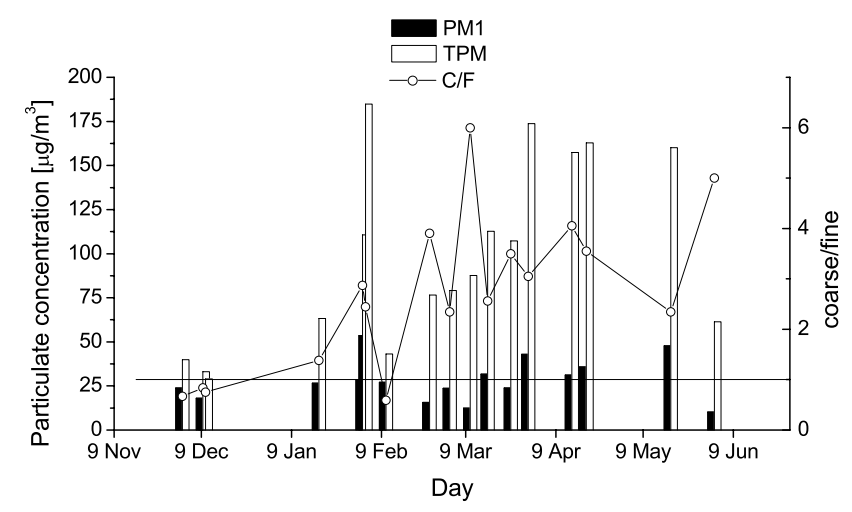

Fig. 10. Concentrations of aerosols observed during the sampling period. TPM denotes total particulate matter and C/F means the ratio between particles with aerodynamic size above and below $1 \mu \mathrm{m}$.

value $28 \mu \mathrm{g} \cdot \mathrm{m}^{-3}$. The ratio $\mathrm{C} / \mathrm{F}$ was generally higher than 1.0 indicating the presence of larger particles. A comparison of Valladolid with other European towns such as Gent (Dingenen et al., 2004), Bern (Hueglin et al., 2005) or Melpitz (Heintzenberg and Bussemer, 2000) indicates that the PM concentrations are predominantly higher in this region of center Spain. This is probably due to the strong contribution of dust soil by the surrounding lands and the frequent desert dust intrusions.

Figure 11 is a time series of the mass specific absorption coefficient of particulate matter with aerodynamic size below $1 \mu \mathrm{m}$. The calculated values for a wavelength of $550 \mathrm{~nm}$ range between $0.4 \mathrm{~m}^{2} \mathrm{~g}^{-1}$ and $4.7 \mathrm{~m}^{2} \mathrm{~g}^{-1}$ with an average value of $1.8 \mathrm{~m}^{2} \mathrm{~g}^{-1}$.

By comparing Figs. 8 and 10 we observe that each increase of the absorption coefficient coincides with a decrease of the ratio $\mathrm{C} / \mathrm{F}$. The situations of $\mathrm{C} / \mathrm{F}<1.0$ are in coincidence with

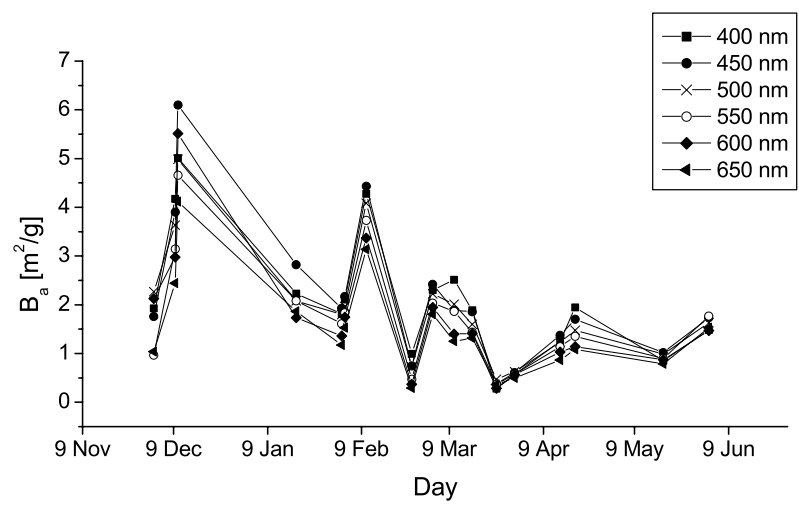

Fig. 11. Mass absorption coefficient of $\mathrm{PM}_{1.0}$.

the highest absorption coefficients measured. On 12 February the ratio $\mathrm{C} / \mathrm{F}$ presents its lowest value of all the campaign, coinciding with the highest $\sigma_{a}$ measured. On this day the TSP concentration is very low because the coarse fraction is very small while the fine fraction remains only slightly higher than the average level. Air masses, whose trajectories were analyzed using the NOAA's HYSPLIT model (Draxler and Rolph, 2003; Rolph, 2003), were coming from northern Spain and Europe suggesting the influence of additional anthropogenic industrial sources. On 12 March the ratio C/F presents the highest value of the all period. On this day the TSP concentration remains at average levels while the fine fraction is smaller and the coarse fraction increases with respect to the average. The absorption coefficient is slightly lower than usual. The air masses were coming from the Atlantic, crossing Portugal and reaching Valladolid from the west. This suggests that the particles are dominated by those of maritime origin.

It is interesting to compare the measured absorption coefficient with that determined using the Mie theory. We used the OPAC package (Hess et al., 1998) and defined a mixture with the proportions and the number density from our filter measurements to estimate the optical characteristics of the aerosol. The estimated average parameters obtained for $550 \mathrm{~nm}$ are a scattering coefficient, $\sigma_{s}=143 \times 10^{-6} \mathrm{~m}^{-1}$, and the absorption coefficient, $\sigma_{a}=31 \times 10^{-6} \mathrm{~m}^{-1}$. The average $\sigma_{a}$ measured for $550 \mathrm{~nm}$ was $45 \times 10^{-6} \mathrm{~m}^{-1}$ which is $\approx 30 \%$ higher than the predicted value. This difference is within the expected error of measurements with the integrating plate measurement. In addition, the estimates from Mie theory require assumptions of particle sphericity and knowledge of the refractive index. Both of these assumptions introduce significant uncertainty in the predicted absorption coefficient.

\section{Conclusions}

A qualitative/semi-quantitative characterization of the morphological and optical properties of aerosol particles has 
been carried out as part of a more extensive and general study about the aerosols in the urban atmosphere of Valladolid. An optical technique (integrating plate) was used to obtain absorption information about the particles collected in the filters. Scanning electron microscopy and energy dispersive $\mathrm{x}$-ray analysis were used for obtaining information about the morphological properties of individual particles and their elemental composition.

Particles of natural and anthropogenic origin were observed with graphitic carbon particles dominating those of anthropogenic origin. These carbon particles were found on all size stages of the impactor but most frequency in the $\mathrm{PM}_{1.0}$ size range. Coal and oil fly ash particles were dominant in the 1 to $2.5 \mu \mathrm{m}$ aerodynamic size range whereas from $1 \mu \mathrm{m}$ to $10 \mu \mathrm{m}$ large amounts of salts were observed, suggesting the presence of a more local source whose location requires further studies.

Black carbon particles are present as an important component of the fine fraction matter and we consider it can be responsible for the majority of the measured visible light absorption. Nevertheless dust also contributes to the absorption on those days where these particles are present in higher concentrations. In general, we observed that the fine mode particles found in the Valladolid atmosphere are more usually related with anthropogenic air pollution whereas the coarse mode is the most abundant mass fraction found and consists mostly of mineral particles with natural origin. This could explain the low to medium values of the absorption coefficient measured.

Acknowledgements. This work was partially supported by the CYCIT Ref. REN2002-00966/CLI. We thank an anonymous reviewer and D. Baumgardner for helpful comments.

Edited by: R. Hitzenberger

\section{References}

Anderson, J., Buseck, P., Saucy, D., and Pacyna, J.: Characterization of individual fine-fraction particles from the Arctic aerosol at SPITsbergen, May-June 1987, Atmos. Environ., 26A, 17471762, 1992.

Bond, T., Anderson, T., and Campbell, D.: Calibration and intercomparison of filter-based measurements of visible light absorption by aerosols, Aerosol Sci. Technol., 30, 582-600, 1999.

Buseck, P. and Pósfai, M.: Airbone minerals and related aerosol particles: Effects on climate and environment, Proc. Nat. Acad. Sci. USA, 96, 3372-2279, 1999.

Casado, H., Encinas, D., and Lacaux, J.: Relationship between the atmospheric particulate fraction and the ionic content of precipitation in an area under influence of a waste incinerator located in the Basque Country (Spain), Atmos. Environ., 30, 1537-1542, 1996.

Chandra, S., Satheest, S., and Srinivasan, J.: Can the state of mixing of black carbon aerosols explain the mistery of 'excess' atmospheric absorption?, Geophys. Res. Lett., 31, L19 109, doi:10.1029/2004GL020662, 2004.
Chou, C., Chen, T.-K., Huang, S.-H., and Liu, S.: Radiative absorption capability of Asian dust with black carbon contamination, Geophys. Res. Lett., 30, 1616, doi:10.1029/2003GL017076, 2003.

Dingenen, R. V., Raes, F., Putaud, J.-P., Baltensperger, U., Charron, A., Facchini, M.-C., Decesari, S., Fuzzi, S., Gehrig, R., Hansson, H.-C., Harrison, R. M., Hüglin, C., Jones, A. M., Laj, P., Lorbeer, G., Maenhaut, W., Palmgren, F., Querol, X., Rodriguez, S., Schneider, J., t. Brink, H., Tunved, P., Tørseth, K., Wehner, B., Weingartner, E., Wiedensohler, A., and Wåhlin, P.: A European aerosol phenomenology 1: physical characteristics of particulate matter at kerbside, urban, rural and background sites in Europe, Atmos. Environ., 38, 2561-2577, 2004.

Draxler, R. and Rolph, G.: (HYbrid Single-Particle Lagrangian Integrated Trajectory) Model access via NOAA ARL READY Website (http://www.arl.noaa.gov/ready/hysplit4.html), NOAA Air Resources Laboratory, Silver Spring, MD, 2003.

Hänel, G. and Hillenbrand, C.: Calorimetric measurement of optical absorption, Appl. Opt., 28, 510-516, 1989.

Hansen, J. and Nazarenko, L.: Soot climate forcing via snow and ice albedos, Proc. Nat. Acad. Sci. USA, 101, 423-428, 2004.

Haywood, J. and Boucher, O.: Estimates of direct and indirect radiative forcing due to tropospheric aerosols: a review, Rev. Geophys., 38, 513-543, 2000.

Heintzenberg, J. and Bussemer, M.: Development and application of a spectral light absorption photometer for aerosol and hydrosol samples, J. Aerosol Sci., 31, 801-812, 2000.

Hess, M., Koepke, P., and Schult, I.: Optical Properties of Aerosols and clouds: The software package OPAC, Bull. Am. Met. Soc., 79, 831-844, 1998.

Horvath, H.: Atmospheric light absorption - a review, Atmos. Environ., 27A, 293-317, 1993.

Hueglin, C., Gehrig, R., Baltensperger, U., Gysel, M., Monn, C., and Vonmont, H.: Chemical characterisation of PM2.5, PM10 and coarse particles at urban, near-city and rural sites in Switzerland, Atmos. Environ., 39, 637-651, 2005.

Kirchstetter, T., Novakov, T., and Hobbs, P.: Evidence that the spectral dependence of light absorption by aerosols is af fected by organic carbon, J. Geophys. Res., 109, D21 208, doi:10.1029/2004JD004999, 2004.

Lin, C., Baker, M., and Charlson, R.: Absorption coefficient of atmospheric aerosol: a method of measurement, Appl. Opt., 12, 1356-1363, 1973.

McMurry, P., Litchy, M., Huang, P., Cai, X., Turpin, B., Dick, W., and Hanson, A.: Elemental composition and morphology of individual particles separated by size and hygroscopicity with TDMA, Atmos. Environ., 30, 101-108, 1996.

Pósfai, M., Simonics, R., Li, J., Hobbs, P., and P.Buseck: Individual aerosol particles from biomass burning in southern Africa: 1. Compositions and size distributions of carbonaceous particles, $\mathrm{J}$. Geophys. Res., 108, 8483, doi:10.1029/2002JD002291, 2003.

Querol, X., Alastuey, A., Viana, M., Rodriguez, S., Artiñano, B., Salvador, P., Santos, S., Patier, R., Ruiz, C., de la Rosa, J., de la Campa, A., Menendez, M., and Gil, J.: Speciation and origin of PM10 and PM2.5 in Spain, J. Aerosol Sci., 35, 1151-1172, 2004.

Ramsden, A. and Shibaoka, M.: Characterization and analysis of individual fly-ash particles from coal-fired power stations by a combination of optical microscopy, electron microscopy and quantitative electron microprobe analysis, Atmos. Environ., 16, 
2191-2206, 1982.

Roberts, D. and Jones, A.: Climate sensitivity to black carbon aerosol from fossil fuel combustion, J. Geophys. Res., 109, D16 202, doi:10.1029/2004JD004676, 2004.

Rodríguez, S., Querol, X., Alastuey, A., Kallos, G., and Kakaliagou, O.: Saharan dust contributions to PM10 and TSP levels in Southern and Eastern Spain, Atmos. Environ., 35, 2433-2447, 2001.

Rolph, G.: Real-time Environmental Applications and Display sYstem (READY) Website (http://www.arl.noaa.gov/ready/hysplit4. html), NOAA Air Resources Laboratory, Silver Spring, MD, 2003.

Rosen, H., Hansen, D., Gundel, L., and Novakov, T.: Carbonaceous particles in the atmosphere, chap. Identification of the graphitic carbon component of source and ambient particulates by Raman spectroscopy and an optical attenuation technique, pp. 229-232, Lawrence Berkeley Laboratory, 1979.
Sánchez, M., Pascual, D., Ramos, C., and Pérez, I.: Forecasting particulate pollutant concentrations in a city from meteorological variables and regional weather patterns, Atmos. Environ., 24A, 1509-1519, 1990.

Vázquez, A., Costoya, M., Peña, R., García, S., and Herrero, C.: A rainwater quality monitoring network: a preliminary study of the composition of rainwater in Galicia (NW Spain), Chemosp., 51, 375-386, 2003.

Wang, C.: A modeling study on the climate impacts of black carbon aerosols, J. Geophys. Res., 109, D03 106, doi:10.1029/2003JD004084, 2004. 